\title{
Racismo, clase social y género en el espacio urbano
}

\author{
Diana Mulinari ${ }^{1}$ y Anders Neergaard ${ }^{2}$
}

\begin{abstract}
SÍNTESIS
El objetivo de este artículo es explorar las diferentes formas a través de las cuales el miedo a la violencia es articulado en el contexto de discursos hegemónicos sobre la "seguridad" ciudadana. Nuestro eje teórico se localiza dentro del marco postcolonial, haciendo eje en la contribución de la teoría para comprender las intersecciones de género, clase y racismo. Metodológicamente el artículo toma su punto de partida en un estudio inspirado por la etnografía crítica focalizando en dos barrios (que difieren en su perfil socioeconómico) en la ciudad de Buenos Aires, Argentina.
\end{abstract}

\begin{abstract}
The article's objective is to explore different forms of articulation of fear of violence in hegemonic contexts of public "security" discourses. Our theoretical framework is based on post colonial studies in intersection with gender, class and racism. Methodologically the article presents a critical ethnography study focussed on two neighborhoods (which differ in their socioeconomic profiles) in the city of Buenos Aires, Argentina.
\end{abstract}

Palabras clave: violencia urbana, "seguridad", miedo, género, racismo. Key words: urban violence, security, fear, gender, racism.

\section{Introducción}

Mira cómo nos obligan a vivir, encarcelados, entre rejas, todo cerrado, una garita de policía en cada manzana (informante en un barrio privilegiado)

Aquí como siempre. Los derechos humanos y la democracia nunca llegaron al barrio (informante en un barrio de clase trabajadora)

En un contexto donde diferentes grupos de ciudadanos están localizados en posiciones radicalmente opuestas (y antagónicas) en relación al acceso a recursos materiales y simbólicos, la violencia urbana significa e implica -como las citas al comienzo de página lo indican- diferentes cosas para diferentes grupos.

Laura Tedesco (2000) identifica una correlación directa entre 
pobreza y violencia en su análisis de la relación entre la distribución de ingreso (índice Gini) y las tasas de criminalidad en la ciudad de Buenos Aires durante el período 1985-1987³. La autora sostiene que la violencia debe ser considerada política en el sentido que refleja y es un efecto de políticas económicas y sociales específicas. Nuestro punto de partida es que más que una ruptura clara, procesos de continuidad pueden ser visualizados entre el terrorismo de Estado de los años setenta y la criminalización de la pobreza del presente.

¿Es posible hablar de violencia urbana en singular o nos enfrentamos a formas altamente diversificadas de la violencia ubicada en espacios y cuerpos específicos? ¿Qué rol cumplen las relaciones de género, clase y etnicidad en la constitución de las formas a través de las cuales la violencia es nombrada en los diferentes espacios ciudadanos?

Nuestro objetivo es tratar de contestar estas preguntas, tomando la experiencia particular y local en el espacio urbano como punto de partida. Nuestro material empírico está basado en un estudio etnográfico de dos barrios con diferentes perfiles socioeconómicos, completando doce meses de residencia en los dos barrios entre 2001-2006.

\section{Puntos de partida teóricos}

Es imposible acercarse a nuestros informantes sin contextualizar el análisis de sus narrativas en los procesos estructurales de transformación socioespacial que han sufrido las ciudades periféricas del llamado "Tercer Mundo". Nuestra comprensión de la violencia está determinada por la localización de nuestra investigación en la ciudad de Buenos Aires, una ciudad global semiperiférica. Este contexto es importante para entender cómo se establece un espacio de la ciudad organizado a través de discursos de miedo y de paranoia frente al "otro". Políticas económicas neoliberales, procesos de desindustrialización, altos niveles de desempleo y migración fronteriza localizada en el sector de trabajo informal (servicio doméstico, construcción, etc.) caracterizan las formas de capitalismo flexible de una ciudad global semiperiférica. El debilitamiento del Estado en la provisión de bienestar, el 
rol altamente ambivalente de la policía como protectora y agresora y la expansión en el mercado de empresas de seguridad definen el marco donde la vida cotidiana y las maneras de definir qué es violento, quién es violento y quién es víctima tienen lugar.

El concepto de violencia ha sido el foco de una serie de debates teóricos. En un intento de sistematizar un modelo para el análisis de la violencia, Philippe Bourgois (2001) identifica cuatro tipos de violencia: la violencia política, la estructural, la simbólica y la cotidiana. La violencia política se refiere a las formas de violencia que son racionalmente administradas a través de una ideología política. La violencia estructural es un concepto elaborado por Johan Galtungs (1975) que expande la noción de violencia a fin de incluir las causas de daño físico (la pobreza, la falta de atención de salud, etc.) que no están directamente relacionadas con la violencia física, sino que se producen a través de relaciones sociales de desigualdad; relaciones sociales que a menudo, directamente o indirectamente, están defendidas por la fuerza y a través de la militarización.

La violencia simbólica, un concepto desarrollado por el sociólogo Pierre Bourdieu, identifica cómo procesos de dominación se reproducen a través del activo des-conocimiento de las estructuras de poder por parte de los grupos dominantes y el uso de la categorización con el fin de marginar y excluir (Bourdieu, 1994, Bourdieu y Wacquant, 1992). El concepto de violencia cotidiana es usado por D'cruze para iluminar la violencia o la posibilidad de violencia "en el centro de la vida cotidiana de las personas" (2000, 12). La antropóloga social Nancy Scheper-Hughes (1992) utiliza el concepto de violencia cotidiana para definir los procesos que normalizan las "pequeñas" brutalidades cotidianas dentro de las comunidades. Estas tipologías, en un diálogo crítico con teorías feministas y postcoloniales han funcionado como conceptos sensibilizadores en el análisis de nuestro material empírico. Nuestro punto de partida esta localizado en una comprensión interseccional (Frankenberg, 1993) de las relaciones de género donde el género se lee siempre como racializado y codificado a través de la clase social. Nuestro punto de partida es en el concepto de racialización (Miles, 1989) para identificar el proceso a través de la cual grupos de personas se construyen como una categoría diferente de personas basadas en nociones de "raza" o etnicidad ${ }^{4}$. 


\section{Puntos de partida metodológicos}

Tomando como punto de partida el debate teórico dentro de la etnografía crítica (Madison, 2005), hemos tratado de refleccionar sobre nuestro rol durante el trabajo de campo. La investigadora Patricia Hill Collins (2000) utiliza el concepto de afuera/de adentro para analizar como grupos históricamente excluidos/ marginados corporalizan posiciones hibridas (Narayan, 1997) dentro de la ciencia y en los procesos de investigación. Nuestra posición como de afuera/de adentro (uno de los miembros del equipo de investigación se conceptualiza como "negro" y el otro se identifica con la ciudad de Buenos Aires a pesar del exilio y la diáspora) fue un punto ventajoso en el trabajo de campo, donde nuestras diferentes identidades crearon una espacio de confianza, intimidad y respeto. Nuestras identificaciones de genero (mujer/hombre) también contribuyeron a diversificar la amplitud y el contenido de las narrativas.

El proyecto etnográfico también implicó una serie de desafíos éticos. En nuestras entrevistas con habitantes del barrio privilegiado, los limites entre un investigador interesado y la de un ciudadano que legitima las opiniones racistas de muchos de nuestros informantes fue difícil de delinear (Bulmer y Solomos, 2004). Algunos de nuestros informantes en el barrio de clase trabajadora expresaban sus emociones en relación a los "criminales", definidos como una amenaza a la comunidad desde dentro, a través de formas de deshumanización muy similares. Muchas veces retornábamos a nuestra casa con la sensación de haber dicho demasiado o demasiado poco.

Hemos llevado a cabo la investigación en Buenos Aires durante un largo período de tiempo (2001-2005). Durante este tiempo hemos vivido en estos dos barrios completando cerca de doce meses de trabajo de campo. La razón central en la selección de los dos barrios son además de perfiles socio-económicos muy diferentes, la presencia de organizaciones de vecinos. Estas organizaciones de vecinos, aunque de manera muy diferentes, son actores centrales en responder a las necesidades de los vecinos en relación a lo que en los barrios era definido como "problemas de seguridad". Hemos completado el trabajo de campo con 25 entrevistas/historia de vida, con valiosos datos provenientes de las organizaciones de derechos humanos, y con análisis de texto de los medios de comunicación. 


\section{Prisiones de privilegio: un barrio "normal"5}

La multitud de estrategias utilizadas para proteger las casas es tal vez el primer impacto que sufre un observador desprevenido. Las puertas de las casas son de acero blindado y las ventanas están protegidas con rejas dobles. Las paredes y vallas tienen astillas de vidrio o de alambre de púas en la parte superior. En algunas casas el símbolo de la empresa de seguridad está colocado al lado de la entrada, en otras está colocado el símbolo de un perro guardián. En las esquina, garitas y juego de luces intermitentes (Thuillier, 2002).

\section{La política del miedo: Entre los trabajadores "decentes" y los criminales peligrosos}

Vivimos confinados. Nadie puede vivir así. Uno no puede salir. La semana pasada una mujer que llevaba un collar de oro estaba entrando en el tren y uno de estos le quiso sacar el collar y como tiró y la mujer se defendió, el tipo la empujó y la mujer se cayó en las vías y murió. Dicen que el muchacho se comportó como si no hubiera pasado nada... que no le preocupó en absoluto, ¿sabes lo que pienso yo? Que hay que matarlos a todos...

¿Sabe usted lo que pasó aquí, sí, aquí, a la vuelta de la esquina? En la estación de tren. Las dos de la tarde... una mujer que llevaba un collar con los anillos de boda de sus padres... y uno de los delincuentes que no tendría más que doce años de edad, trató de sacárselo con la ayuda de un cuchillo y terminó poniéndole el cuchillo en la garganta de la mujer. Ellos son asesinos... asesinos... Alguien dijo, fue un bolita (forma racista de conceptualizar a ciudadanos que han migrado de Bolivia), pero no se trata de nacionalidad, tenemos el mismo tipo de gente aquí, estamos llenos de negros (derogatorio) en el barrio.

Muchas (sino todas) las conversaciones con los residentes del barrio incluían la presencia de historias con una estructura narrativa similar en la cual se representa a la víctima como una mujer de edad (blanca) y el autor se construye como un hombre joven (racializado). La narración se construye también a través 
de estrategias que permiten al narrador subrayar las características específicas de los autores del ataque, características que están reguladas por procesos de racialización.

La dos narrativas que hemos presentado son las voces de dos informantes sin ningún tipo de contacto entre sí. Ninguno de ellos había sido testigo del incidente y la persona que les había contado la noticia tampoco era testigo presencial. A pesar de esta ausencia de "hechos", los dos no dudaban en la veracidad de la información recibida.

El antropólogo Michael Taussig (1984) muestra el papel central que las narrativas sobre el otro juegan en la normalización de la violencia. La violencia, argumenta el autor, se normaliza en un proceso alimentado por el silencio y los mitos que funcionan a través de rumores y fantasías. En nuestro estudio este tipo de narrativas/rumores se entrelazaban con los medios de comunicación (Rotker, 2000) que cumplen un papel central no sólo en la creación y desarrollo de una cultura del miedo sino en la categorización y la criminalización del otro.

Emociones como el miedo no sólo pueden explicarse a través del aumento de actos violentos. No hay relación directa entre niveles de miedo y aumento de violencia. El papel que los medios de comunicación desempeñan en la creación, desarrollo y profundización de estos temores ha sido analizado por el investigador colombiano Jesús Martín Barbero que argumenta "que los medios viven gracias al miedo de todos" (2000). Es a través de la televisión con sus imágenes de la ciudad violenta que la violencia entra en la vida cotidiana de los ciudadanos. Dichas imágenes que a menudo representan de manera altamente problemática a los grupos menos privilegiados y que crean límites claros entre el orden (representado por la "clase media blanca") y el caos (representado por la población urbana en situación de pobreza y conceptualizada como mestiza o indígena).

Estamos visitando a uno de estos miembros (una mujer) de la coordinadora de vecinos; sentados en la sala y el televisor está encendido. El noticiero de las ocho de la noche muestra a la policía atrapando a un hombre joven (que trata de cubrirse el rostro con un suéter). La cámara se desplaza hacia otro ángulo, mostrando manchas de sangre, se mueve hacia una mujer anciana llorando, y hacia las caras silenciosas de lo que parecen ser vecinos de un barrio con pocos recursos. La secuencia entera no dura 
más de medio minuto y es acompañada de una voz (autoritaria y masculina) del periodista quien mirando directamente a la cámara pregunta retóricamente: "más violencia en la ciudad ¿cuánto más tenemos que soportar?" El periodista no ofrece ninguna información sobre el contexto o el contenido del acto violento.

La secuencia está en el centro de producción de los medios de comunicación que crean y estructuran los discursos sobre la violencia urbana. Beatriz mira primero la imagen de la televisión, después nos mira a nosotros, suspira y nos dice: "Así como ves ahí, así es nuestra vida. ¿Crees que exagero? Mira la televisión y que te confirmen que no estoy exagerando. Esta ciudad es una jungla. Yo hace años que no salgo de noche. Nunca se sabe lo que esta gente puede hacer".

El evento al que la secuencia de televisión se refería era un conflicto violento entre dos grupos de traficantes de drogas. Sin embargo, ella se siente seriamente amenazada. El lugar de este evento está situado a kilómetros y privilegios de distancia de donde estamos tomando té con Beatriz. Los discursos de los medios de comunicación representan lugares de violencia como espacios compartidos, si bien los espacios en la ciudad se caracterizan por segregación y exclusión. Los medios de comunicación crean una noción de un ser colectivo (nosotros) amenazado por grupos específicos de personas pobres racializados (los otros). Dicho discurso permea la vida y la subjetividad de los grupos privilegiados dentro de la ciudad; aunque nunca hayan sufrido ningún tipo de violencia individualmente (Lupton y Tulloch, 1999).

Este es un extracto de una larga conversación con uno de nuestros informantes, Marcelo, quien ha participado en la organización de una red de vecinos contra la delincuencia en la zona:

Son animales. Ellos están en las drogas y son bestias. La policía los tiene que matar directamente, porque si no, los envían a la justicia, los tribunales de menores y ese tipo de cosas, y salen después de tres días. No, hay que matarlos dos veces, con un último disparo en la cabeza, el tiro de gracia por si acaso... y la policía los conoce, saben quiénes son, no les tendría que permitir que entraran en el barrio... Bueno, no quiero decir todo el mundo... hay un montón de gente decente que viene al barrio para trabajar, pero en general se sabe quiénes son estas personas. En este momento si sos padre de familia no tenés 
respiro. Yo me acuerdo del tiempo, no sé, como hace treinta años cuando salíamos en la tarde para charlar con los vecinos en el porche... ahora mi esposa y mis hijas están siempre adentro y con alarmas por todas partes... No, no se puede vivir así. Vivimos con miedo. Y yo soy un simple ciudadano, yo no soy un político o un magnate ... no tendría que ser así, que un simple ciudadano y su familia se vean obligados a vivir con miedo.

Nos gustaría hacer hincapié en la diferencia que Marcelo hace entre el ciudadano y la familia porque en nuestro material el género es un principio central de organización social que crea una oposición binaria entre el hombre (que protege) y la mujer (que debe ser protegida). Una de las estrategias a través de la cuales formas de masculinidad privilegiada se constituyen es mediante el rol de proteger "la casa y la familia". En su narrativa Marcelo construye límites claros entre su subjetividad como varón y la identidad de su mujer y sus hijas, ubicándolas en la esfera privada. En la narrativa de Marcelo el discurso de la seguridad también se constituye a través de estrategias racistas en la construcción del otro. Marcelo está absolutamente convencido de que los supuestos atacantes son fácilmente identificables, reconocibles físicamente, no pertenecen, no solamente a la vecindad, sino a la definición de lo nacional que Marcelo representa. Aunque Marcelo no ha usado la palabra "negros" o "cabecitas", el subtexto racializado es claro en su análisis. La presencia del otro en el barrio (los otros que son de afuera) nombra la nueva división internacional del trabajo reproductivo, con la inserción en el mercado informal del trabajo doméstico de las mujeres migrantes (Sassen, 1991, Sassen, 1999).

Esta presencia (o mejor dicho la ambivalencia a esta presencia) es un tema al que vuelven muchos de nuestros informantes. Las narrativas sobre trabajadoras domésticas involucradas en actos "criminales" son diversas y múltiples.

Este es el relato de Cecilia:

Bueno, vos sabes muy bien, las cosas no son como eran antes. Mi abuela tenía una Santiagueña (persona con orígenes en la norteña provincia de Santiago del Estero) y cuando llegó el momento de jubilarse, dijo que quería quedarse en la casa... así era... Se llamaba Anita y para mí era parte de la familia... Pero ahora es diferente, esta gente es diferente, no tiene moral, 
lo único que le interesa es ganar dinero... Mi vecina tenía una boliviana y parecía muy silenciosa y agradable... y un día no volvió más y le dejó una factura telefónica desorbitante y le llevó toda la ropa de cama...

La intervención de Cecilia, como la de Marcelo, también invocan el pasado, un pasado que añoran donde la labor afectiva era una parte fundamental de las relaciones laborales clientelistas entre las mujeres migrantes en el servicio doméstico y las mujeres privilegiadas de etnicidad blanca (Chaney y García Castro, 1989, Anderson, 2000). Un pasado en que los niveles de comodificación del cuerpo del otro eran tan extremos que Cecilia usa el verbo tener (en terminos de ser propietario de) en relación a otro ser humano. En la narrativa el pasado se enfrenta a un presente en el que las mujeres trabajadoras son definidas como inmorales y materialistas, con una agenda diferente y amenazante. Los mismos prejuicios racistas y la misma falta de reflexión sobre el privilegio de clase y de etnicidad que permite a una mujer la superexplotación de otra mujer aparecen en la narrativa de Myriam:

El problema no son las chicas, el problema es el lugar donde viven y los novios. Porque una no debe pensar que son santas. No, porque una sabe lo que hacen cuando salen... que van a esos bailes, y ahí bailando con esa música, todos los paraguayos... o los bolivianos o personas de las provincias del interior... y las chicas frente a estos hombres, dan a conocer nuestras direcciones... y de repente cuando menos lo pensás, los tenés parados a esos tipos en la puerta de tu casa... Y esto me pasó a mí... Y yo le dije, nunca un hombre aquí de nuevo. Vos y yo estamos bien. Nos hacemos compañía.

Aquí funciona el espacio (del otro) y la masculinidad (del otro) como el eje amenazador de la paz laboral creada entre Myriam y la empleada doméstica. Detrás de los argumentos de Myriam se encuentra el deseo de que la persona trabajando en su casa regule su vida de manera tal que sus relaciones afectivas o íntimas se limiten a su relación con la empleadora que la obliga "a sentirse si fuera de la familia" (termino usado por Myriam). 


\section{Negociación entre diferentes pasados y (diferentes) presentes}

Otro elemento importante en muchas de las narrativas de nuestros informantes es la construcción de un pasado donde se vivía sin miedo. Existe entre nuestros informantes un pasado de orden y de integración (a menudo en recuerdos de la infancia de los informantes) y un presente de caos y fractura. Es interesante señalar que la comprensión de Marcelo del pasado como un tiempo seguro encarna una narración de una ciudad que no ha sido amenazada por la dictadura militar. Marcelo, a pesar de identificar el pasado en treinta años atrás, no hace ninguna reflexión en su narrativa sobre que la seguridad se sitúa en la dictadura militar (Bosco, 2006). Sin embargo esto no quiere decir que apoye el rol de los militares en relación a los derechos humanos:

Lo que los militares han hecho es terrible. Uno ve esta pobre mujer en el televisor. Ella que es maestra, tiene una hija desaparecida y está buscando a su nieta. Esta mujer, son gente decente, trabajadora. Vivían cerca de este barrio... Es una locura... Yo no sabía nada de estas cosas... pero es terrible... Mucha gente dice que lo que necesitamos aquí es una mano dura... pero yo digo que no, aquí nadie quiere que los militares vuelvan... Lo que necesitamos es que la policía y el sistema de justicia empiecen a hacer su trabajo. Y que los piqueteros se dejen de tocar el bombo y vayan a trabajar. Mi abuelo era un inmigrante, y vino aquí con una mano adelante y otra atrás y se sacó la mugre, trabajó, trabajó y construyó una casa para él y una para cada uno de sus hijos... pero estas personas no quieren trabajar... no es que no hay trabajo... no quieren trabajar.

Nos gustaría que el lector notara la noción de gente decente que rodea la representación que Marcelo tiene de las víctimas de la dictadura militar. La cita está refiriéndose a una entrevista de televisión con una de las abuelas de Plaza de mayo (Tedesco, 2005). No creemos que sea una interpretación exagerada sugerir que en la cosmovisión de Marcelo los crímenes cometidos por los militares son mucho más graves porque se cometieron contra gente "decente", es decir contra personas a quienes Marcelo construye como iguales, con quien puede (hoy) identificarse. Pero hay otra conexión en torno a la noción de decencia: la que existe entre los migrantes decentes (como el padre de Marcelo, 
que vino de Italia a finales de 1930) y los migrantes de ahora, esta categorización refuerza los subtextos racistas entre inmigrantes de antes (europeos blancos) y de la actualidad. Marcelo se mueve en su narrativa entre los nuevos migrantes (que no quieren trabajar) y los piqueteros (que deberían trabajar) cuya intervención política Marcelo infantiliza a través del argumento del bombo. Sin duda, la presencia de los piqueteros perturba el "libre" movimiento de los grupos privilegiados en la ciudad, ligando el miedo al otro en el barrio con la amenaza que se experimenta por la presencia "incontrolada" de los otros en las calles:

Una cosa son los cartoneros... Bueno, uno ya sabe qué son y que van a venir... y además es un trabajo. Pero esto es muy diferente, es algo diferente con este lío de los piqueteros, todos los días, con toda esta gente por todas partes que nunca se sabe si se puede llegar al centro de la ciudad, si te van a dejar pasar... es una vergüenza, mujeres con chicos...

Escuchando seriamente estas (y similares) voces, aparecen fuertes emociones, no sólo una sensación de estar amenazados, sino una amenaza basada en encontrar al "otro" fuera de su lugar "natural"'6. Una ilustración de estas emociones fue capturada cuando viajábamos en auto con otra de nuestras informantes. María se detiene por un semáforo en rojo. Inmediatamente un niño, de seis o siete años, trata de acercarse ofreciéndose para limpiar las ventanillas del auto. María dice que no, pero el niño sigue insistiendo. Ella dice que no de nuevo, esta vez a los gritos. El niño deja de limpiar las ventanas, se retira, pide perdón pero María sigue gritando. Unos minutos más tarde se vuelve hacia nosotros. Creemos que María se avergüenza, que siente que nos debe pedir disculpas:

“Están en todas partes, en todas partes. Son tantos. Y nunca se sabe. Sus padres los envían a trabajar. Uno les da dinero y para nada. Y nunca se sabe... parecen sumisos pero estos son los que te pueden matar por un peso".

La ansiedad emocional, el terror que vimos expresado en el rostro de María frente a un niño de menos de seis años, capta con precisión el sentimiento de inseguridad que muchos ciudadanos de sectores privilegiados experimentan. Pero María no fue amenazada 
(de hecho ella amenazó al niño). Queremos hacer hincapié en que lo que la informante identifica como una amenaza no es lo que puede entenderse como un acto violento, es el mero hecho de que está obligada a compartir el mismo espacio urbano. Es la presencia del otro lo que es una amenaza.

\title{
Los hombres como protectores y perpetradores
}

\begin{abstract}
¿Quién te va a proteger? ¿La policía? Son terriblemente corruptos y mafiosos, son iguales que los otros. Y las empresas de seguridad... dicen que son mano de obra desempleada de la época de la dictadura. Ahora que han perdido sus puestos de trabajo ... vuelvo a casa con mi padre o mi hermano.
\end{abstract}

El concepto de mano de obra desempleada en relación a los trabajadores de las empresas de seguridad destaca la experiencia histórica de la triple A, los paramilitares fascistas que actuaban antes y durante la dictadura, asesinando figuras públicas de izquierda, tales como abogados, periodistas y activistas políticos. El proceso democrático dejó sin trabajo a estos grupos y nuestra informante Cristina no es la única voz que hace notar esta conexión entre el ser un miembro de la triple A en el pasado y trabajar para las empresas de seguridad en el presente.

Siempre le digo a la nena (su hija) que ella debe tener cuidado y no tomar ningún taxi que no conozca... Y mi marido siempre la espera en la puerta.

La afirmación de que los hombres pueden proteger a las mujeres es un tema importante de discusión. Una de las consecuencias centrales de la dictadura militar ha sido la fractura de las familias por el asesinato y encarcelamiento de miembros y el exilio interno y externo. Otra ha sido la cohesión forzada de la familia nuclear heterosexual en un contexto donde los espacios públicos y reuniones colectivas eran peligrosos. Si bien el proceso democrático ha abierto otras formas de identificación y solidaridad, fuera de lo privado, el enfoque en la seguridad re-articula la familia (y los hombres dentro de la familia) como el único lugar seguro, reforzando la oposición binaria entre un patriarcado protector y otro amenazante. 


\section{Privilegio(s), vulnerabilidad y el derecho a castigar}

Un diálogo entre dos vecinos, ocurrido en una de las reuniones de la coordinadora por la seguridad del barrio, ilumina las tensiones existentes entre los ciudadanos sobre el contenido y el rol de la democracia:

N 1. No es sólo que la policía es corrupta... El problema es que no pueden hacer nada... ¿qué querés que hagan? Si respetan la ley... entonces nunca agarran a nadie... La delincuencia no se detiene por todas estas consideraciones jurídicas... estos animales deberían ser sacrificados en el lugar donde se encuentran, y desde chicos, no hay que dejarlos crecer.

N 2. Espere un momento... ¿qué querés? Qué quieren; los militares de vuelta una vez más... De vuelta la marchita... ¿querés que la policía pueda salir de vuelta a matar? Vos estás muy, muy loco.

N 1. No, no me entendiste. Esto no tiene nada que ver con los militares. Yo soy el primero en defender la democracia, pero estas personas son antidemocráticos... no se los puede detener con las leyes... ellos hacen lo que quieren... están drogados.

Pareciera que existe un consenso amplio en la crítica a la dictadura militar entre estos sectores de clase media. Los grupos que defienden el accionar de los militares durante la dictadura continúan siendo minoritarios. La fractura en el respeto por los derechos humanos se abre desde otra perspectiva, donde al mismo tiempo que se reconoce como abominable el accionar de los cuerpos represivos durante la dictadura se construye al otro a través de estrategias de deshumanización, de manera tal que su integridad corporal se coloca dentro de una lógica afuera de los procesos democráticos.

Pero no es sólo a través de los medios de comunicación que los discursos sobre la violencia ciudadana se desarrollan, el discurso sobre la "mano dura" con la delincuencia se refuerza y profundiza a principios del año 2000 en el contexto de formas cada vez más extendidas de movilización social (incluyendo el corte de rutas) para exigir el derecho al trabajo y desafiar las políticas neoliberales. Estas formas de resistencia han tenido lugar en la periferia tanto en la zona norte como en la zona sur desde hace más de veinte años. Es la presencia del otro en el espacio urbano donde la amenaza se visualiza. 
Nuestros informantes calculan la cantidad de dinero que usan para protegerse (Tilly, 1998). La lista es larga, el guardia del barrio (200 dólares) las puertas blindadas (3000 dólares) la alarma (6000 dólares). Uno de los miembros (hombre) del consejo de vecinos afirmó que:

Quiero defender, proteger a mi familia. Y quiero que nos organicemos en el barrio de manera que podamos estar más tranquilos... Yo apoyo el lema de cero tolerancia contra la delincuencia, yo apoyo la guerra contra la delincuencia, porque es una guerra... pero a pesar de todo, nada cambia, y estamos cada vez peor.

Este informante no experimenta cambios en su vida cotidiana a pesar de que las medidas represivas se han expandido. Tal vez porque los que sufren los cambios son los que han sido el objeto de las mediadas represivas, para estos grupos la situación (como lo discutiremos a continuación) se ha empeorado en relación a sus derechos como ciudadano.

El hijo del empresario Juan Carlos Blumberg fue en 2004 secuestrado y posteriormente asesinado. Teniendo el caso Blumberg como punto de partida se articula por primera vez un discurso colectivo y público exigiendo mayor seguridad y protección contra la violencia. Se produjeron una serie de demostraciones, una de las más concurridas movilizando alrededor de cien mil manifestantes. La interpelación de Blumberg, que también se extendió fuera de Buenos Aires y Argentina a través de visitas de Blumberg a otros países, entre otros Estados Unidos, se transformó en demandas políticas a través de los medios de comunicación, la administración de Kirschner se sintió presionada a apresurar reglas más severas en el sistema carcelario.

La interpelación efectuada por Blumberg a los sectores de clase media ha tenido hasta cierto punto éxito, creando un contexto en que la única respuesta a la violencia que crece con la polarización social es el aumento de las medidas represivas adoptadas por el Estado (Wacquant, 2004). Las instituciones han respondido con mayor violencia estatal y "mano dura" al desafío de la violencia urbana. Promesas de "Limpiar la ciudad" es una de los slogan más comunes a través de las cuales las carreras de ciertos políticos se constituyen. Es importante subrayar que este discurso toma como punto de partida el cuestionamiento a los 
derechos humanos, argumentando que dicho respeto es un obstáculo en la "guerra contra el crimen".

\section{Las cárceles de la miseria: “Nosotros también somos un barrio decente"}

Vamos a cambiar nuestro enfoque; de un barrio privilegiado a un barrio de clase trabajadora. El hecho de que se tarde aproximadamente dos horas en bus y/o en tren para movilizarse entre los dos barrios es un espejo de la segregación espacial sistemática en la ciudad.

\section{Espacios vulnerables}

Utilizamos el concepto de espacios vulnerables para captar las experiencias cotidianas de las personas que residen en un barrio de clase obrera en las zonas periféricas que rodean el centro de la ciudad.

Usamos el concepto de vulnerabilidad para identificar la relación de este grupo de ciudadanos con las instituciones estatales, especialmente la policía y el sistema judicial que a menudo son a la misma vez una amenaza real y una ausencia seria. Masculinidades vulnerables designa la posición de los hombres jóvenes que sufren procesos de racialización (cabeza negra, bolita, chilote, etc.), en el contexto de formas de desempleo estructurales. Estas condiciones impiden el cumplimiento de las normas tradicionales de masculinidad, la identidad basada en la capacidad (masculina) de proveer para la familia, de ser "decente" como hombre de clase trabajadora, se les niega rotundamente. La tensión entre el consumo ostentoso evidente en el centro de la ciudad, la noción de una "buena vida" transmitida por la televisión por un lado y la falta de alternativas político-culturales por el otro pone a estos jóvenes en contextos de alto riesgo.

Algunos de los grupos de derechos humanos han comenzado a identificar una continuidad entre la dictadura y la democracia en la violación de los derechos humanos. Como Ángel, un activista de la CORREPI (Coordinadora Contra la Represión Policial), desempleado de veintidós años de edad que sugiere: 
La policía no fue el blanco de la ira popular después de la derrota de Malvinas y no sufrió la experiencia de estigmatización que sufren los militares. No estoy diciendo que las organizaciones de derechos humanos no han denunciado el papel de la policía en los años setenta, pero el foco... ¿cómo podría decirlo?... el odio fuerte aquí, es contra los militares, contra Videla y Astiz... Así que tenemos una fuerza policial con los hábitos y las conductas de la dictadura. Tal vez en realidad estamos hablando de dos instituciones, cuando hablamos de la policía: la Federal es más colegial y profesional y la Provincia que es más clientelista, según las denuncias la peor. Bueno, claro la de la Provincia actúa en los barrios periféricos y ahí se permite todo todo todo. El problema es que no hay visiones... la derecha quiere más policías y quiere que la policía tenga más derechos legales, mano dura... y la izquierda no quiere, no acepta dice solo no no no... y eso tampoco sirve...

La mayoría de los investigadores coinciden en que la policía de Buenos Aires es un ejemplo primordial de la falta de responsabilidad democrática (Méndez, 1999) en una institución estatal. Las violaciones graves y sistemáticas a los derechos humanos no están limitados al terrorismo de Estado de los años setenta, sino que han tomado nuevas formas después de la institucionalización de la democracia.

Ramiro, que tiene un hermano en la cárcel y trabaja con los familiares que sufren represión policial en la zona, refuerza lo dicho por Ángel:

Si usted ve cómo los militares están en la cárcel... ellos viven mejor que nosotros aquí en el barrio... Pero por otro lado en los últimos cuatro años la población carcelaria del país aumentó de 30 a 50 mil y sólo en la Provincia de Buenos Aires el número ha pasado de 16 a 25 mil... Es imposible discutir, imposible tener una discusión racional... lo único que dicen es más presos, más cárcel, más policías, hay que exterminar a los delincuentes...

Manuel tiene 52 años de edad y es uno de los miembros más activos de CORREPI en el barrio, excepcional tanto por su género (la mayoría de los miembros de CORREPI son mujeres), por su edad (la mayoría de los miembros varones son casi adolescentes) y por su situación laboral (no es desempleado sino trabaja como repartidor en un supermercado). 
El número de personas muertas por la policía desde 1983 hasta 2002 es de 1300, fíjense las estadísticas no es sólo a través de la cantidad de asesinatos, sino la brutalidad policial que va en aumento, la tortura y la violencia física. Le daré sólo un ejemplo: en 2001, la Corte Suprema de Justicia se vio obligada a crear una entidad especial para registrar todas las denuncias de tortura de menores de edad que ocurrían cuando estaban en custodia.

El termino "gatillo fácil" nombra la práctica policial que se caracteriza por la utilización irresponsable del armamento (a menudo con resultados mortales), especialmente en las zonas periféricas más marginales (Fuentes, 2004). El concepto de ciudadanía es extremadamente relevante aquí. Nuestro trabajo de campo muestra una ciudad fracturada en espacios antagónicos que funciona a través de relaciones muy diferentes con el Estado y sus instituciones. Algunos lugares dentro de la ciudad están protegidos por la policía y las fuerzas de seguridad privadas, así como por los discursos que identifican a los grupos étnicamente mayoritarios conceptualizados como blancos, como nopeligrosos. Otras partes de la ciudad no sólo se encuentran sin protección (a través de una desvinculación de las obligaciones del Estado para sus ciudadanos), sino también amenazada por los discursos racistas que construyen al otro como la amenaza y por las políticas de Estado que no sólo han históricamente colaborado en la construcción de categorías racistas sino que criminalizan la pobreza. Manuel continúa su charla:

La mayoría de los casos de "gatillo fácil" no tienen lugar en La Recoleta (en el centro), pero en las afueras de la ciudad. Los que los sufren son los cartoneros, los vendedores ambulantes, los chicos jóvenes... Un "cabecita negra" en el lugar equivocado en el momento equivocado, especialmente si son jóvenes... y eso es suficiente para que la policía se de el derecho de actuar... bueno, y cuando ellos actúan , ya sabés lo que pasa...

Los patrones de racialización y la criminalización de la pobreza interactúan con políticas públicas que tienden a tratar a las víctimas de delitos en la periferia, como si fueran delincuentes ellos mismos, en el contexto de un Estado nacional cuya forma más sistemática de resolver los conflictos sociales ha sido (y sigue siendo) mediante la represión policial. 


\section{Masculinidades vulnerables}

La socióloga feminista Raywan Connell (1999) propone un enfoque en el estudio de la violencia que en vez de centrarse en la violencia de género como categoría analítica, se focalice en identificar qué tipo de masculinidades, definidas como construcciones culturales, son más propensas a ser violentas. La autora afirma que, al mismo tiempo que las masculinidades hegemónicas controlan el aparato del Estado incluyendo a los militares y la policía y están implicados en la violencia institucional, las masculinidades subordinadas articulan formas de violencia en contra de sí mismos y sus propias comunidades. En el contexto de desempleo, exclusión social y represión, una carrera delictiva es una alternativa racional que ofrece formas de pertenencia para muchos jóvenes. La racionalidad de la elección la elabora una joven (embarazada) que será el único sostén de su familia. Su marido está en la cárcel, enfrentando una condena por robo a mano armada.

¿Qué querés que hagan? Las escuelas en estos barrios nunca están abiertas. Cuando no están en huelga los maestros... Alguien vandaliza el edificio. No hay trabajo. Uno va a buscar un trabajo y hay trescientos en la cola y te piden referencias. Siempre amenazados por la policía... Su vida no vale nada... Y entonces piensan, un sólo robo, una última vez.... creen que pueden zafar (salvarse)... que le van a poder comprar la casa a la vieja (la madre)... que van a poder viajar... hacen tantos planes...

María, la madre de un niño de diecisiete años asesinado por la policía en 2004, comparte su experiencia:

Parece que había habido un robo en el centro y al oficial de policía se le ocurrió que Pipi tenía un arma, pero nadie vio el arma. Pipi sólo tenía un teléfono celular... y le disparó dos veces. Sus amigos lo llevaron a casa, yo lo llevé directo al centro de salud a las tres de la mañana y se me muere delante de mí a las seis... Y me dicen que mi hijo, que era sospechoso, porque tenía, porque andaba con ropa cara... Pero era por el club... Porque él era entrenador acá en un club cerca de casa y el club le había dado la ropa... Pero para la policía si Pipi vivía en este barrio y vestía bien, entonces Pipi era un ladrón. 
María, como muchos otros familiares, ha logrado pasar de la tragedia individual hacia formas de organización para exigir justicia, desafiando los discursos que criminalizan a sus hijos y proyectan la responsabilidad de las instituciones del Estado a los padres:

Lo primero que me dijeron fue que estaba en las drogas... que era un adicto a las drogas. Él no lo era. Pregunte a cualquiera por aquí. Si se pasaba en el club entrenando y ni tomaba cerveza los sábados si tenía partido el domingo. Pero decime una cosa, aunque él hubiese estado en las drogas ¿Tienen derecho a matar a un chico de diecisiete años de edad?

Si bien la sociedad argentina ha dado pasos muy importantes hacia la democratización a través de los juicios a los involucrados en la violación de los derechos humanos durante la dictadura es imposible no identificar una continuidad autoritaria en el discurso contra el crimen, tres décadas más tarde. La frase "por algo se los llevaron" corporaliza la complicidad de una parte amplia de la población legitimando la persecución que sufrieron los activistas políticos durante los años setenta. Una mujer joven, Mercedes, con dos niños pequeños reflexiona sobre una frase similar en los siguientes términos: "La gente dice, y bueno si la policía lo maltrató, no hay fuego sin humo".

Las organizaciones de derechos humanos no sólo hablan de la criminalización de la pobreza, sino de la criminalización de la protesta cívica. Especialmente después de los acontecimientos de los 19 y 20 de diciembre de 2001, donde murieron dos jóvenes activistas políticos de los barrios de clase obrera en manos de la policía (Filippini, 2001). También afirman que la policía federal, la gendarmería y la prefectura interactúan impidiendo que las movilizaciones populares puedan trasladarse de sus barrios en la periferia hacia el centro de la ciudad.

La voz de un activista del vecindario nos habla de una experiencia diferente sobre qué es la violencia y quién es el blanco de la violencia. Julio es activo en el comedor comunitario que el barrio organiza desde los años noventa: "Mire, señora, si uno es pobre y joven y si vive en este barrio, uno ya es boleta (asesinado)".

Los mayores índices de violencia se encuentran en los barrios periféricos (y no las zonas de clase media alta que son centrales en la definición del discurso de la delincuencia). La relación 
ambivalente con la policía que define la relación entre los barrios pobres y el Estado puede considerarse una medida de la crisis del Estado en la zona (Stanley, 2005). Al mismo tiempo de que la mayoría de los ciudadanos en el barrio con quienes hablamos critican a la policía, por la falta de presencia policial en la zona, una crítica basada fundamentalmente en cómo los recursos del Estado son repartidos de manera desigual entre sus ciudadanos:

Si usted va al centro de la ciudad, donde están los bancos no se puede mover, hay dos policías por cada persona, pero en el barrio, cuando teníamos un violador, un violador de niños, tuvimos que organizarnos con la cooperativa de la escuela y con los padres para acompañar a los niños a la escuela... la policía nunca entra en el barrio. Un secuestro de una rubia en Martínez (zona residencial de clase media alta) y sale cada cinco minutos en la televisión... pero aquí pueden matar diez y nadie sabe nada... y no les importa un comino.

La narrativa muestra una experiencia de violencia que "no es noticia" (como nos explica otros de los habitantes del barrio con el que hablamos). La experiencia de los habitantes del barrio no interviene en el flujo de noticias de los medios de comunicación.

La noción de la rubia de Martínez expresa la relación directa entre clase y etnicidad en Buenos Aires, donde la norma de ser blanco (y europeo) regula las jerarquías sociales. Nuestro informante elige deliberadamente describir los ciudadanos de la zona de Martínez a través del color de su pelo. Por otro lado, la relación entre los habitantes de este barrio y la policía están determinados por la experiencia histórica de la institución policial:

mala gente hay en todas las clases sociales, pero acá entre nosotros, los que eligen ser policías son la Resaca, los que no sirven para nada ...Son los que les es más fácil entrar en la policía ya que ahí, pueden robar tranquilos, roban con el apoyo de la institución, con sus tarjetas de identidad de la policía.

Las narrativas que hemos recogido en el barrio difieren altamente de las narrativas en el barrio de clase media. Una diferencia central es que los límites espaciales entre "nuestro lugar" y el de los "criminales", que era un argumento relevante en las narrativas en el barrio privilegiado, ocupan otro lugar en las narrativas en el barrio obrero. Es cierto que algunos criminales 
son conceptualizados como intrusos en el barrio, pero en la mayoría de los casos los criminales son percibidos como "viviendo entre nosotros". La presencia de la violencia y la delincuencia es en el barrio periférico un fenómeno cotidiano que nadie cree puede desaparecer o al menos contenerse (como en las narrativas de los barrios privilegiados). La experiencia de que la violencia es constituyente del espacio vital; en combinación con la ambivalencia hacia la policía, lleva a otras estrategias.

Daniel Goldstein (2005) ha explorado las formas de responder a la delincuencia en su estudio de diferentes barrios en Cochabamba, Bolivia, con especial énfasis en las formas a través del cual la lógica neoliberal y la condición del lenguaje mediático regulan las experiencias y las respuestas. El autor sostiene que los ciudadanos bolivianos están adoptando actitudes flexibles hacia el crimen y que con frecuencia recurren a mecanismos que van de organizaciones de auto-ayuda, a patrullas de seguridad privada a linchamientos.

Si bien se podría argumentar que los habitantes de los barrios privilegiados viven con miedo y que el riesgo de ser secuestrado o robado es una experiencia que marca su vida cotidiana, también podría decirse que estos ciudadanos han sido capaces de consumir "protección" en términos de la variedad de productos que ofrece la industria de la seguridad. Es en las zonas periféricas, donde en el contexto de la ausencia de la policía las formas de autodefensa a menudo culminan en tragedias. Las dos narrativas a continuación son una ilustración de este argumento:

Yo no lo vi. Pero mi hija estaba barriendo la vereda y escuchó los tiros... Ella lo conoce al nene.. Fueron juntos a la escuela. Me dijeron que el hombre que lo mató; el dueño de la almacén había sido asaltado siete veces. Y que estaba tan cansado... Dios mío, qué tragedia...

Yolanda se refiere aquí a la muerte de un niño de diez años en manos de un vecino que había disparado su arma cuando el muchachito intentó entrar en su jardín con el fin de robar unos adornos del árbol de Navidad. El niño murió en el acto (Página 12, 12 de diciembre de 2002). Mientras que las estrategias desarrolladas en los barrios privilegiados para defender la propiedad y la familia son aceptadas como las acciones "responsables" de los ciudadanos en cuestión, los ciudadanos en el barrio de la 
periferia, se ven obligados a defenderse y a menudo sus acciones individuales (desesperadas) contra la delincuencia son representadas en los medios de comunicación como primitivas y salvajes. Amalia, una mujer de setenta años que es dueña de una pequeña tienda en el barrio sostiene que:

Y ahora dicen en la televisión que son animales. ...Pero usted sabe lo que es tener a un violador en el barrio o estos asesinos traficantes de drogas que usan a los niños de siete años de correos. Y además la policía que es cómplice, van $50 \%$ - 50\% ... Bueno, se lo digo y si lo desea, escríbalo ... si me levanto una mañana y los veo en la esquina haciendo business [en Inglés] No voy a molestarme en llamar a la policía. Porque o no vienen o son socios y los apoyan.. ¿sabes cuántos adolescentes, cuanta gente joven salvaría su vida si estos tuvieran un tiro en la cabeza?

Cristina una joven madre que trabaja media jornada en un restaurant, apoya el argumento de Amalia:

Uno piensa, sobre todo si se es madre, si uno tiene hijos, que alguien los tiene que matar, de otra manera no podemos detenerlos, nada puede detenerlos.

Apoyar y legitimar en el nombre de la maternidad actos de violencia para proteger a los hijos y el barrio era un discurso recurrente entre algunas mujeres del barrio. Si bien las mujeres se representan a sí mismas como no violentas, apoyan activamente las prácticas violentas con el objetivo de proteger a sus hijos.

Sin embargo, la presencia de armas de fuego en la comunidad, como muestran las estadísticas y a pesar de las fantasías que lleva a muchos de estos jóvenes hacia carreras criminales en la mayoría de las carreras, no solo lleva a la cárcel o la muerte, sino también tienen como consecuencia un gran aumento en el nivel de violencia interpersonal en la comunidad.

Dicen que le robó a otros distribuidores de drogas. Nadie sabía dónde estaba. Pero se volvió loco. Fue a la casa de su madre. A la madre la conozco porque vive en la cuadra siguiente, una mujer decente, y empezó a gritar y tirar cosas y cuando la hermanita la quiso defender a la madre, sacó un revolver y la mató. Pobre, de catorce años. La madre está desvastada. 
Estaba borracho y alguien le había dicho que ella estaba viendo a su primo. Él la mató a ella, y a los niños que dormían en la misma cama y luego se suicidó.

Javier Auyero (2000) ilustra las conexiones entre la violencia estructural ejercida por el neoliberalismo en la Argentina y el auge de la delincuencia y el abuso de sustancias en las villas miserias de la ciudad de Buenos Aires. Un argumento similar es desarrollado por el antropólogo Bourgois para quien el comercio de drogas corporaliza la violencia estructural y simbólica, donde la desigualdad social y la miseria se expresan a nivel de los conflictos interpersonales entre personas socialmente vulnerables, a través de la violencia que ejercen contra si mismo (a través de las drogas ) a sus familiares (a través de la violencia doméstica) sus vecinos y la comunidad (con robos, tiroteos etc.).

Es importante advertir la centralidad de las relaciones (patriarcales) de género en la tendencia a localizar en las mujeres la causa principal de estos procesos. Paralelamente a los análisis de nuestros informantes que identificaban las relaciones injustas entre el centro y la periferia de la ciudad como centrales en las causas de la violencia en el barrio, la mayoría de las explicaciones que recogimos que explicaban la violencia a nivel individual tendían a focalizar en el rol de las mujeres. A pesar de que la mayoría de los informantes analizan el problema de la comunidad en terminos sociológicos (distribución de la riqueza, fractura del rol del Estado, etc.) en la discusión de carreras criminales o víctimas específicas muchos utilizan un discurso que culpabiliza a la mujer como madre o como novias en tanto se argumenta que ellas no han podido (o no han sabido) controlar a sus hijos (la madre nunca se preocupaba, no estaba en casa) o a sus esposos (ella salía con otros por eso él empezó a drogarse). Paradojalmente, las mujeres que en general son las que más sufren las consecuencias de las carreras criminales de los hombres son identificadas dentro del marco de las ideologías patriarcales no como las víctimas de la violencia sino como las responsables de evitarla. 


\section{Conclusión}

En este artículo hemos argumentado que el discurso sobre la seguridad está intrínsecamente vinculado a los procesos de polarización urbana, proceso de polarización que debe ser leído a través de categorías interseccionales que permitan comprender cómo las relaciones de clase se constituyen a través de relaciones de género y etnicidad. Nuestro objetivo en este artículo no es entablar un debate sobre si la violencia urbana ha aumentado, una pregunta que se continúa discutiendo y cuya respuesta demanda la solución de serios problemas metodológicos en relación a la conceptualización de lo que es violencia y qué instrumentos son fructíferos para medirla.

Nos hemos centrado en narrativas sobre (in)seguridad entre los habitantes de dos barrios muy diferentes de la ciudad de Buenos Aires, Argentina. Afirmar que los sentimientos de temor se basan sólo en la creación de discursos hegemónicos podría inducir a un error. Indudablemente ha habido un aumento de la violencia en las grandes ciudades de América Latina de acuerdo a Arriagada y Godoy (1999).

Nuestro foco está en una tensión general, en el estudio de la violencia, en la que existe entre los sentimientos de miedo y los riesgos (reales) a sufrir violencia. La mayoría de las investigaciones muestran una relación invertida entre estos dos aspectos. Los que se encuentran en menor situación de riesgo son, en general, los que expresan más miedo e inseguridad.

Este estudio ha investigado esta paradoja tratando de comprender las historias de violencia y las narrativas de miedo en dos barrios. Para concluir, nuestro objetivo es ampliar esta discusión en relación a la presentación teórica al inicio del artículo. Basándose en Bourgois (2001) que distingue entre cuatro diferentes formas de violencia (política, estructural, simbólica, cotidiana) para organizar las historias de nuestros informantes, trataremos de capturar por un lado las diferencias entre las narrativas de los informantes de los diferentes barrios, y por otro lado los vínculos entre ellas.

En las narrativas de ambos grupos de informantes es difícil encontrar material empírico que podría clasificar la violencia que sufren hoy en día como violencia política, en la definición de Bourgois, la violencia racionalmente administrada a través de 
una ideología política clara. Nuestros informantes utilizan la noción de la violencia política sobre todo para identificar el período comprendido entre 1976 y 1984, es decir, el término es reservado para el tiempo de la dictadura. Sin embargo; algunas narrativas vinculan la violencia actual con el espacio de la política. Los informantes en las zona privilegiadas nombraron la movilización de los piqueteros como una amenaza a su propio espacio (a pesar de que las movilizaciones no eran violentas, ni atentaban contra personas o bienes). Algunos de los informantes en el barrio obrero definían la represión policial como una forma de restricción de las posibilidades de lucha política, identificando una continuidad con la represión en la época de la dictadura. Esta vinculación se expresa en la expansión del concepto de derechos humanos a las víctimas del gatillo fácil.

Si bien no se articula a través del uso del concepto de violencia estructural la mayoría de nuestros informantes del barrio de clase trabajadora incluían en sus narrativas, tanto sobre las víctimas como sobre los perpetradores, el contexto de desempleo y aumento de la pobreza. Las narrativas en el barrio de clase media, eran rara vez reflexiones sobre la violencia estructural. La violencia se entendía, principalmente, como intrínsecamente vinculada a ciertas categorías de personas (racialización) y a la falta de normas morales (en otros grupos).

El discurso de "el otro" que sustenta la mayor parte de las narrativas en el barrio de clase media puede ser visto como un principio central en la práctica de las formas de violencia simbólica. La distinción entre las personas "decentes" y los delincuentes (termino usado por los informantes) era una parte importante en la mayoría de las narrativas presente en ambos barrios, pero en diferentes maneras. En la zona privilegiada, esta distinción estaba estrechamente relacionada con las categorizaciones de un "nosotros" y "el otro", categorizaciones basadas en concepciones racistas del "otro" fuertemente vinculadas a los habitantes de los barrios periféricos. Los informantes de los barrios de clase obrera estaban mucho menos centrados en categorías racistas en las narrativas sobre el grupo de perpetradores. Esto no significa que la distinción entre las personas decentes y los delincuentes no existiera. En lugar de categorizaciones racistas, la categoría de delincuentes no se equipara con un grupo pre-determinado, sino que se considera como la suma de los individuos que 
cometen crímenes violentos, haciendo hincapié en las decisiones individuales y las carreras criminales. En este sentido, la atención se centra en mayor medida en las razones emocionales y familiares que llevaron a una persona a convertirse en un criminal, el impacto de las acciones sobre las personas que viven en el barrio y las estrategias para hacer frente a esta violencia. La mayoría de las narrativas de nuestros informantes de la zona de clase trabajadora, hacen hincapié en las formas de violencia simbólica, a través de las cuales ellos y todo el vecindario son estigmatizados tanto por grupos privilegiados como por la policía. A pesar de la crítica a la policía por ser corrupta, ineficiente y al sistema judicial por no tomar en serio la violencia en los barrios periféricos, las narrativas de la zona de clase obrera crean una conexión entre la violencia simbólica que los criminaliza e impide conceptualizarlos como víctimas y la violencia cotidiana que experimentan.

El género es un principio de organización central en todas las narrativas, localizando a los mujeres y a los hombres en diferentes posiciones en relación no solo al Estado sino demarcando el rol de víctima, protector y perpetrador. Las mujeres del barrio privilegiado fueron las que más expresaban miedo a la violencia, a ser atacadas, violadas, secuestradas. Las mujeres del barrio de clase obrera en cambio no hacían especial hincapié en su persona y estaban más centradas en sus hijos adolescentes, sus hermanos varones, sus maridos y sus hijas en edad escolar. Nuestro material identifica diferentes formas de corporalizar una identidad femenina. Los discursos de género forman a las mujeres privilegiadas como débiles y necesitando protección, y a las mujeres de clase obreras como "fuertes" con la responsabilidad de proteger a otros.

Las narrativas de nuestros informantes identifican diferentes formas de entender la violencia y nos ayudan a entender como un discurso de miedo (al otro) se articula. El análisis de las narrativas de un barrio privilegiado muestran una conexión clara entre privilegio, miedo, preocupación por la seguridad y un sentimiento de intrusión a través de la presencia del otro (racializado). Estas narrativas son muy diferentes de las que hemos recogido en el barrio obrero, donde la conexión más identificable era entre vulnerabilidad, violencia cotidiana y sentimientos que variaban entre el desamparo y la organización colectiva. 
El género es un elemento fundamental en todas las narraciones localizando a las mujeres y a los hombres en diferentes posiciones en relación no solo al Estado sino demarcando el rol de víctima, protector y perpetrador.

\section{Notas}

1 Centro de Estudios de Género, Universidad de Lund, Suecia. diana.mulinari@genus.lu.se

2 REMESO. Research on ethnicity and migration, Universidad de Linköping, Suecia.

3 Los estudios sobre aumento y formas de violencia confrontan dificultades metodológicas en relación a la conceptualización del objeto de estudio. Dichos problemas metodológicos crean dificultades en términos de comparaciones nacionales. También es muy difícil mostrar relaciones exactas entre desigualdad social y aumento del crimen: Para profundizar la discusión ver entre otros: HOJMAN, D. E. (2002) Explaining Crime in Buenos Aires: The Roles of Inequality, Unemployment, and Structural Change. Bulletin of Latin American Research, 21, 121-128, n TEDESCO, L. (2000) La nata contra el vidrio: urban violence and democratic governability in Argentina. Bulletin of Latin American Research, 19, 527-545.

4 Para profundizar la discusión ver: Grosso (2005), Hopenhayn (2001), Staab and Maher (2006), Van Dijk (2003).

5 Término usado por los habitantes del barrio.

6 Para profundizar la discusión sobre la experiencia de los piqueteros ver: Auyero (2004); Dinerstein (2007)

\section{Bibliografía}

Anderson, B. Doing the dirty work?: the global politics of domestic labour. London: Zed, 2000.

Arriagada, I. y Godoy, L. Seguridad ciudadana y violencia en América Latina: diagnóstico y políticas en los años noventa. Santiago de Chile: CEPAL, 1999.

Auyero, J. ìThe hyper-shantytown: neo-liberal violence(s) in the Argentine slumî. En Ethnography 1, 2000, 93-116.

Auyero Jr. Vidas beligerantes. Quilmes: Editorial Universidad de Quilmes, 2004.

Bosco, F. ìThe Madres de Plaza de Mayo and Three Decades of Human Rightsí Activism: Embeddedness, Emotions, and Social Movementsî. En Annals of the Association of American Geographers, Volume 96, Issue 2 June. Routledge, 2006, 342-365.

Bourdieu, P. Language and symbolic power. Cambridge, MA: Harvard University Press, 1994.

Bourdieu, P. y Wacquant, L. J. D. An invitation to reflexive sociology. Chicago: University of Chicago Press, 1992. 
Bourgois, P. ìThe Power of Violence in War and Peaceî. En Ethnography 2, 2001, 5-34.

Bulmer, M. y Solomos, J. (Eds.) Researching Race and Racism. London: Routledge, 2004.

Chaney, E. M. y García Castro, M. (Eds.) Muchachas no more: household workers in Latin America and the Caribbean. Philadelphia: Temple University Press, 1989.

Collins, H. P. "Itís All in the Family: Intersections of Gender, Race and Nation". En Narayan, U. y Harding, S. (Eds.) Decentering the Center. Philosophy for a Multicultural, Postcolonial and Feminist World. Bloomington: Indiana University Press, 2000.

Connell, R. Maskuliniteter. Göteborg: Daidalos, 1999.

DíCruze, S. (Ed.) Everyday Violence in Britain, 1850-1950: Gender and Class. Harlow: Longman-Pearson Education, 2000.

Dinerstein, A.C. "Lessons from a Journey: the Piquetero Movement in Argentina". En Bonefeld, W. (ed) Subverting the Present- Imagining the Future: Insurrection, Movement, Commons, Autonomedia. New York, 2007.

Filippini, L. The Popular Protests in Latin America. Buenos Aires: CELS -Centro de Estudios Legales y Sociales-, 2001.

Frankenberg, R. White Women. Race Matters. The Social Construction of Whiteness. New York: Routledge, 1993.

Fuentes, C. S. "La inevitable ìmano duraî: sociedad civil y violencia policial en Argentina y Chile". En Revista de Ciencia Política 24, 2004, 3-28.

Galtung, J. Peace: research, education, action. Copenhagen: Ejlers, 1975.

Goldstein, D. M. “Flexible Justice: Neoliberal Violence and ëSelf-Helpí Security in Bolivia". En Critique of Anthropology 25, 2005, 389-411.

Grosso, José Luis. Politicas de la diferencia: interculturalidad y conocimiento. Ponencia presentada en el Primer Seminario Internacional (Etno) educación. Multiculturalismo e Interculturalidad, Universidad del Cauca-Universidad Pedagógica Nacional ñ Flape, Bogotá, noviembre 2-4 de 2005.

Hojman, D. E. "Explaining Crime in Buenos Aires: The Roles of Inequality, Unemployment, and Structural Change". En Bulletin of Latin American Research 21, 2002, 121-128.

Human Rights Watch. World Report. Washington: Human Rights Watch, 2005.

Lupton, D. y Tulloch, J. "Theorising fear of crime: beyond the rational/irrational opposition". En British Journal of Sociology 50, 1999, 507-23.

Madison, D. S. Critical ethnography: method, ethics, and performance. Thousand Oaks, Calif.: Sage, 2005.

Martín-Barbero, J. “La ciudad: entre medios y miedos”. En Rotker, S. (Ed.) Ciudanias del miedo. Caracas: Editorial Nueva Sociedad, 2000.

Méndez, J. "Problems of Lawless Violence: Introductionî. En Méndez, J., Oídonnell, G. y Pinhero, P. S. (Eds.). The (Un)Rule of Law and the Underprivileged in Latin America. Notre Dame: University of Notre Dame, 1999.

Miles, R. Racism. London: Routledge, 1989.

Narayan, U. Dislocating cultures. New York: Routledge, 1997.

Sassen, S. The global city: New York, London, Tokyo. Princeton, N.J.: Princeton University Press, 1991.

Globalization and its Discontents. Essays on the New Mobility of People and Money. New York: New Press, 1999.

Staab, S y Maher, K. “The Dual Discourse About Peruvian Domestic Workers in 
Santiago de Chile: Class, Race, and a Nationalist Project". En Latin American Politics y Society - Volume 48, Number 1, Spring, 2006, 87-116.

Scheper-Hughes, N. Death without weeping: the violence of everyday life in Brazil. Berkeley: University of California Press, 1992.

Stanley, R. "Controlling the Police in Buenos Aires: A Case Study of Horizontal and Social Accountability". En Bulletin of Latin American Research 24, 2005.

Taussig, M. "Culture of Terror--Space of Death. Roger Casementís Putumayo Report and the Explanation of Torture". En Comparative Studies in Society and History 26, 1984, 467-497.

Tedesco, L. "La ñata contra el vidrio: urban violence and democratic governability in Argentina". En Bulletin of Latin American Research 19, 2000, 527-545.

------. "The democratic state and human rights in Argentina and Brasil". En Assies et al Citizenship and political transformation in Latin America. Dutch University Press y el Colegio de Michocan, 2005.

Thuillier, G. Gated Communities in the Metropolitan Area of Buenos Aires (Argentina): A Challenge for Town Planning. Toulouse: University of Toulouse II-Le Mirail, 2002.

Van Dijk, Teun A. Dominación etnica y racism discursive en España y America Latina. Barcelona: Gedisa, 2003.

Wacquant, L. Las Cárceles de la Miseria. Buenos Aires: Manantial, 2004.

Staab, S and Maher, K. "The Dual Discourse About Peruvian Domestic Workers in Santiago de Chile: Class, Race, and a Nationalist Project". En Latin American Politics y Society - Volume 48, Number 1, Spring 2006, 87-116.

Grosso, José Luis. Políticas de la diferencia: interculturalidad y conocimiento. Ponencia presentada en el Primer Seminario Internacional (Etno) educación, Multiculturalismo e Interculturalidad. Universidad del Cauca ñ Universidad Pedagógica Nacional ñ Flape, Bogotá, noviembre 2-4 de 2005.

Hopenhayn, Martin. “¿Integrarse o subordinarse? Nuevos cruces entre política y cultura". En Mato, Daniel. Cultura, política y sociedad. Perspectivas latinoamericanas. Buenos Aires: FLACSO, 2001.

[...] por ejemplo las leyes que alargan las condenas por robo a mano armada y por delitos de armas. Las nuevas leyes aumentan la extensión de las penas acumulativas para delitos violentos a cincuenta años, restringen drásticamente la posibilidad de libertad provisional para los acusados. Además, un proyecto de ley aprobado por la legislatura de la ciudad de Buenos Aires en septiembre modifica el código de la ciudad por delito menor con el objeto de aumentar las sanciones por faltas menores a un máximo de sesenta días de detención, un período más largo que el previsto en el Código Penal para algunos delitosî (Human Rights Watch, 2005). 